\title{
Successful Surgical Treatment of Mitral Valve Endocarditis Caused by Staphylococcus Lugdunensis
}

\author{
Khaled E. Al Ebrahim, MBBCH, FRCSC \\ Department of Surgery, Faculty of Medicine \\ King Abdulaziz University, Jeddah Saudi Arabia \\ khaled_alebrahim@yahoo.com
}

\begin{abstract}
Staphylococcus lugdunensis, a very virulent coagulase negative species, has been recently recognized, and rarely reported in few cases, as a cause of endocarditis. This infection, in contrast to the ordinary staphylococcus epidermidis, is frequently lethal and carries a very high risk of devastating embolic complications. In this paper, it was reported that aggressive infection in a child presenting with mitral valve endocarditis, major left cerebral infarction, bulbar palsy and incontinence, with a favorable outcome after combined medical and surgical treatment in King Abdulaziz University Hospital - Open Heart Unit. The aim of this report is to emphasize the importance of detailed and advanced microbiological identification of the exact coagulase negative species to avoid overlooking an aggressive pathogen.

Keywords: Endocarditis, Staphylococcus lugdunensis infection, Heart valve surgery, Stroke.
\end{abstract}

\section{Introduction}

Staphylococcus lugdunensis was first described in $1988^{[1]}$ and reported as a cause of serious infection including endocarditis, osteomyelitis and septicemia $^{[2]}$. It produces bound coagulase and occurs as a commensal on human skin. Less than $5 \%$ of native valve endocarditis is caused by

Correspondence \& reprint requests to: Dr. Khaled E. Al Ebrahim

P.O. Box 80215, Jeddah 21589 Saudi Arabia

Accepted for publication: 18 November 2006. Received: 27 September 2006. 
coagulase negative staphylococci, mostly epidermidis which normally presents as a subtle, subacute, or chronic illness; where as, S. lugdunensis increasingly appears to more closely resemble that of Staphylococcus aureus - being aggressive and associated with high mortality and complications including systemic embolization, congestive heart failure annular abscesses and disruption of valve leaflets ${ }^{[3,4]}$. Early surgical intervention, commonly valve replacement, is recommended in these cases.

\section{Case Report}

A 13-year-old boy, with no significant past medical history, was admitted to King Abdulaziz University Hospital (KAU) through the Emergency Room with high grade fever, rigors, and night sweats for the last five weeks which was relieved with Tylenol intake. He was complaining also of generalized weakness, fatigue, nausea, vomiting, anorexia, and weight loss of about 5 kilograms over the last month. $\mathrm{He}$ noted erythematous macular rash on the extremities 2 days prior to admission. There was no past history of dental procedure or upper respiratory tract infections. He received three different courses of antibiotics and one course of antimalarial medication, prescribed by the general clinic, with no improvement.

On examination, the patient was conscious, oriented, pale and dyspnoea; respiratory rate was $22 / \mathrm{min}$; heart rate $135 / \mathrm{min}$; blood pressure $116 / 65 \mathrm{mmHg}$; temperature $38.9^{\circ} \mathrm{C}$; normal jugular venous pressure; and mild left lower limb ankle edema. Chest examination showed equal air entry with normal vesicular breathing, abdomen was soft, with tender mild hepatosplenomegaly. Neurological system was grossly intact, heart examination revealed muffled first heart sound, normal second heart sound with pan systolic murmur over the mitral area.

Investigation showed hemoglobin of $10 \mathrm{gm} / \mathrm{dl}$; white blood count (WBC) $20.7 \times 10 / 1$; normal platelet count; normal electrolytes; urea; and creatinine. Liver function tests showed normal bilirubin, mild elevation of transaminases and alkaline phosphatase. Hepatitis and HIV screenings were negative.

Chest X-ray showed cardiomegaly. Echocardiography revealed thickened mitral valve leaflets, severe mitral regurgitation with 2 
vegetations $(0.7 \times 0.8 \mathrm{~cm}$ and $0.3 \times 0.6 \mathrm{~cm})$ attached to both anterior and posterior leaflets, respectively. Mild tricuspid regurgitation, ejection fraction was normal with mild left atrial and ventricular dilatation. Electrocardiogram (ECG) showed sinus tachycardia. Abdominal ultrasound showed slight hepatosplenomegaly.

The patient was started on empiric antibiotics initially including ceftriaxone $1 \mathrm{gm}$ every 12 hours, gentamycin $70 \mathrm{mg}$ three times daily and vancomycin $1 \mathrm{gm}$ twice daily. Three days after admission, the patient suddenly developed loss of consciousness, Glasgow Coma Scale was down to $6 / 15$, with bilateral dilated reactive pupils, and right-sided marked weakness of both upper and lower limbs associated with aphasia and inability to swallow. Magnetic resonance imaging (MRI) of the brain showed acute embolic infarction in the left middle cerebral artery territory (frontoparietal). The patient was tachypneic, tachycardic, and hypotensive. He was transferred to the intensive care unit (ICU), intubated and mechanically ventilated, requiring inotropic support and vasoconstrictors to maintain adequate perfusion pressure. He continued to have high grade fever. Blood cultures were positive for coagulase negative staphylococcus that was subsequently identified as $S$. lugdunensis. Ceftriaxone was changed to Flucloxacillin $2 \mathrm{~g}$ every 4 hours. The patient remained hemodynamically unstable, febrile, and suffered temporary deterioration of renal function over a 10-day-period, followed by gradual improvement and eventually was ex-tubated 12 days later. Follow-up transthoracic and transeosophageal echocardiogram confirmed the previous findings. The patient was transferred to the medical ward with dense right-sided hemiplegia, bulbar palsy, aphasia, lack of both urinary and bowel control, inability to stand and was fed by nasogastric tube. He was followed-up by cardiology, infection control, and neurological teams. The patient was referred to cardiac surgery after completion of 6 weeks of antibiotics and intensive physiotherapy.

Intraoperatively, the left atrium was dilated and the mitral valve was not suitable for repair as it was heavily diseased with vegetations on both leaflets. The valve was excised and replaced with a tissue perimount valve, which has relatively good durability, to avoid the complications of anticoagulation. The patient was weaned of pump well, hemostasis was secured and the rest of the operation was smooth. Postoperatively, the patient was ex-tubated within a few hours and started mobilization and 
feeding on the following morning. Intensive chest physiotherapy was instituted. Valve cultures did not grow any bacteria. The patient's general condition improved, regained swallowing, continued on intensive course of physiotherapy and discharged home with close medical follow-up.

\section{Discussion}

$S$. lugdunensis is a novobiocin-susceptible, coagulase negative species found among the normal flora of skin and mucous membranes and described as a rare cause of endocarditis ${ }^{[3-6]}$.

In general, most coagulase negative staphylococcal infections are nosocomial, increasingly resistant to multiple antibiotics, and, like $S$. aureus, about $80 \%$ of strains produce an inducible beta-lactamase and are methicillin resistant. The increasing incidence of coagulase negative staphylococcal native valve endocarditis is caused by the increased use of indwelling intravascular catheters. S. lugdunensis is considered the most virulent strain since the infection is usually aggressive because of the above features and in addition their ability to secrete bound, not free, coagulase, a feature it shares with $S$. aureus. Bound coagulase has the ability to bind vitronectin and fibrinogen to extracellular matrix ${ }^{[7]}$. This may explain the toxemia, the destructive nature and the embologenic feature of this pathogen. Early identification of these virulent strains, using the most recent microbiological detailed techniques - especially the detection of the coagulase fibrinogen affinity factor and the ornithine decarboxylase activity - is very crucial to avoid delayed treatment ${ }^{[8]}$. Their colonies are usually hemolytic, sticky, yellow or tan, about 2-4 mm in diameter after 48-hours incubation and have a characteristic odor.

Based on the world literature, only 73 cases of $S$. lugdunensis endocarditis have been reported ${ }^{[5,6,9-15]}$. Fifty-seven $(78 \%)$ patients had native valve endocarditis mainly mitral involvement and frequently complicated by heart failure, abscess formation and embolism. Surgery was needed in $51 \%$ of cases and mortality was $42 \%$. Nine (12\%) patients had prosthetic valve endocarditis, mainly aortic, and were associated with abscess formation, required surgery with high mortality (78\%). Pacemaker lead endocarditis was seen in seven (10\%) patients with better prognosis when medical treatment is combined with surgery. 
With the patient, the infection was very aggressive causing severe toxemia requiring mechanical ventilation and inotropic support also resulting in serious neurological deficits in the form of massive left frontoparietal infarction, bulbar palsy, aphasia and incontinence of urine and stool. Early surgical intervention is recommended in these cases.

The message we conclude from this case, which is also emphasized by other reports, is to remember that endocarditis due to $S$. lugdunensis has a different natural history and prognosis than does endocarditis caused by other coagulase negative staphylococcal strains. Early identification of the pathogen and the prompt institution of the proper medical and surgical management are important to avoid the morbidity and mortality of this serious infection.

\section{References}

[1] Freney J, Brun Y, Bes M, Meugnier H, Grimont F, Grimont PAD. Staphylococcus lugdunensis sp. nov. and Staphylococcus schleiferi sp. nov., two species from human clinical specimens. Int J Syst Bacteriol 1988; 38: 168-72.

[2] Patel R, Piper KE, Rouse MS, Uhl JR, Cockerill FR 3rd, Steckelberg JM. Frequency of isolation of Staphylococcus lugdunensis among staphylococcal isolates causing endocarditis: a 20-year experience. J Clin Microbiol 2000; 38(11): 4262-4263.

[3] Diekema DJ, Pfaller MA, Schmitz FJ, Smayevsky J, Bell J, Jones RN, Beach M; SENTRY Partcipants Group. Survey of infections due to Staphylococcus species: frequency of occurrence and antimicrobial susceptibility of isolates collected in the United States, Canada, Latin America, Europe, and the Western Pacific region for the SENTRY. Antimicrobial Surveillance Program, 1997-1999. Clin Infect Dis 2001; 32 (Suppl 2): S114132.

[4] Hellbacher C, Tornqvist E, Soderquist B. Staphylococcus lugdunensis: clinical spectrum, antibiotic susceptibility, and phenotypic and genotypic patterns of 39 isolates. Clin Microbiol Infect 2006; 12(1): 43-49.

[5] Anguera I, Del Rio A, Miro JM, Matinez-Lacasa X, Marco F, Guma JR, Quaglio G, Claramonte X, Moreno A, Mestres CA, Mauri E, Azqueta M, Benito N, Garcia-de la Maria C, Almela M, Jimenez-Exposito MJ, Sued O, De Lazzari E, Gatell JM; Hospital Clinic Endocarditis Study Group. Staphylococcus lugdunensis infective endocarditis: description of 10 cases and analysis of native valve, prosthetic valve, and pacemaker lead endocarditis clinical profiles. Heart 2005; 91(2): e10.

[6] Van Hoovels L, De Munter P, Colaert J, Surmont I, Van Wijngaerden E, Peetermans WE, Verhaegen J. Three cases of destructive native valve endocarditis caused by Staphylococcus lugdunensis. Eur J Clin Microbiol Infect Dis 2005; 24(2): 149-152.

[7] Leung MJ, Nuttall N, Pryce TM, Coombs GW, Pearman JW. Colony variation in Staphylococcus lugdunensis. J Clin Microbiol 1998; 36(10): 3096-3098.

[8] Koh TW, Brecker SJ, Layton CA. Successful treatment of Staphylococcus lugdunensis endocarditis complicated by multiple emboli: a case report and review of the literature. Int $J$ Cardiol 1996; 55(2): 193-197. 
[9] Seenivasan MH, Yu VL. Staphylococcus lugdunensis endocarditis - the hidden peril of coagulase-negative staphylococcus in blood cultures. Eur J Clin Microbiol Infect Dis 2003; 22(8): 489-491.

[10] Garcia Fernandez FJ, Berjon Reyero J, Ruiz Quevedo V, Arcos Lage El E. [Staphylococcus lugdunensis endocarditis. Case report and review of the literature] Rev Clin Esp 2003; 203(2): 98-99.

[11] Sotutu V, Carapetis J, Wilkinson J, Davis A, Curtis N. The "surreptitious Staphylococcus": Staphylococcus lugdunensis endocarditis in a child. Pediatr Infect Dis $J$ 2002; 21(10): 984-986.

[12] Sanchez P, Buezas V, Maestre JR. [Staphylococcus lugdunensis infection: Report of thirteen cases]. Enferm Infecc Microbiol Clin 2001; 19(10): 475-478.

[13] Renzulli A, Della Corte A, Torella M, Dialetto G, Cotrufo M. Mitral and aortic valve endocarditis due to Staphylococcus lugdunensis. Tex Heart Inst J 2000; 27(1): 67-69.

[14] Kragsbjerg P, Bomfim-Loogna J, Tornqvist E, Soderquist B. Development of antimicrobial resistance in Staphylococcus lugdunensis during treatment-report of a case of bacterial arthritis, vertebral osteomyelitis and infective endocarditis. Clin Microbiol Infect 2000; 6(9): 496-499.

[15] Farrag N, Lee P, Gunney R, Viagappan GM. Staphylococcus lugdunensis endocarditis. Postgrad Med J 2001; 77(906): 259-60. 


\section{عملية قلب ناجحة لحالة عدوى تجرثم صمامات القلب بفصيلة

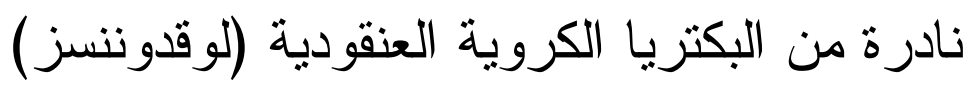

\section{خالد إبر اهيم الإبر اهيم}

قسم الجر/حة ، كلية الطب، جامعة الملك عبدالعزبز جلة - المدلكة العربية السعودية

المستخلص. تم إجر اء عملية قلب ناجحة لطفل أصــبب بتجــرثم الصمام التاجي بفصيلة نادرة شرسة من البكتريا الكروية العنقودية. أدخل المريض المستشفى بشكوى حرارة شديدة مستمرة مع اعتلال

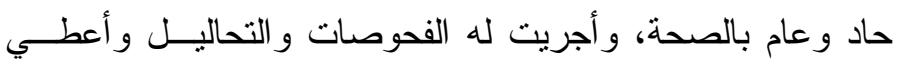

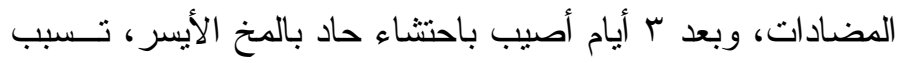

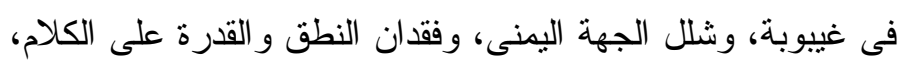

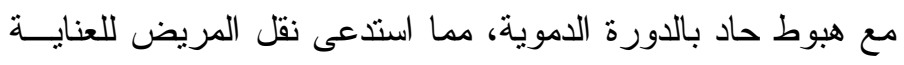

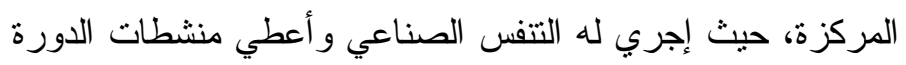

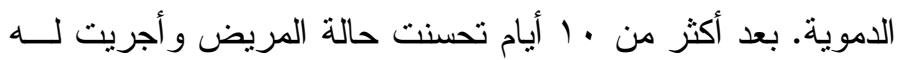

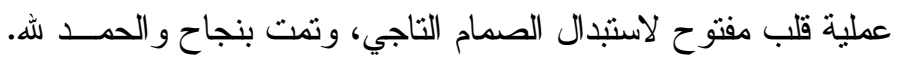

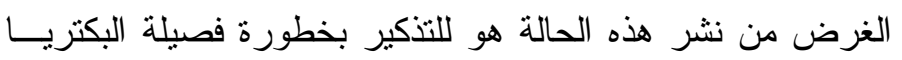

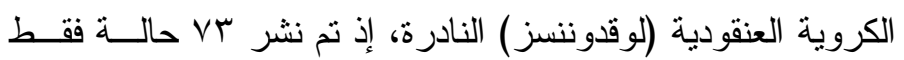
على المستوى العالمي. 